\title{
Experimental Teaching of Econometrics and Cultivation of Student's Creative Ability
}

\author{
Yun Xu \\ Experimental Teaching Centre \\ Economics and Management School of Wuhan University \\ Wuhan, China \\ jacquesxu@21cn.com
}

\author{
Ying Ma \\ Centre for Economic Development Research \\ Wuhan University \\ Wuhan, China \\ yingma9494@126.com
}

\begin{abstract}
As econometrics increasingly grows mature, the experimental teaching of econometrics becomes especially important. The thesis contemplates and studies such issues as the purposes, methods and cultivation of student's creative ability in experimental teaching of econometrics. The so-called experimental teaching refers to providing appropriate real background for the theories and methods to arouse students experience the necessity and effectiveness of each theory and method, understanding corresponding theories and methods in this process through thorough analysis on the problems to be solved in reality. Cooperation between institutions results in platforms of econometric courses. It can be joined to form an integrated platform so that the students can share course resources from other schools and conduct network communication with students and teachers from other schools. The teaching method must be reformed to strengthen cultivating creative spirit and ability. Teacher should exert brand new education and impact on students. Difference should be made in such aspects as difficulty of selected subject and experimental requirement.
\end{abstract}

Keywords-component; econometrics; experimental teaching; creative

\section{INTRODUCTION}

Econometrics is an economic subject appeared in 1930s. Its advent is the objective need for people to study economic phenomenon and activities. Compared to traditional economics, it has a short history but has shown strong vitality. Economic phenomenon and process are the unification of quantity and quality, which inevitably requires analysis from both quantity and quality in terms of research method. Frisch (R. Frisch, 1926), a Norwegian economist, defines econometrics as the combination of economic theory, statistics and mathematics. From this definition, we can see the comprehensiveness of econometrics. It is an economic subject or a branch of economics, belonging to an interdisciplinary subject integrated with arts and science instead of applied mathematics or applied statistics.

Since 1970s, econometrics has entered a new stage for development, manifested by extensive application of computer and proposal of abundant calculation methods, more and more econometric models and variables. Seen from the entire developing process of econometrics, it has obvious difference from mathematics and statistics. Econometrics studies economic issues in reality, so it must be based on clear understanding of economic phenomenon. Besides, design of theoretical model and collection of statistical data must be guided under the economic theories. Instead of relying upon using mathematical tools alone for accomplishment, economic theories also need to be applied for estimation of model parameters and inspection, etc.

In July 1998, the Teaching Guidance Committee of Economics of the Ministry of Education assigns econometrics as one of the key courses for the majors of economics in higher education institutions. At present, most schools have taken econometrics as an important fundamental course for the major of economic management. After years of exploration, the teaching of econometrics, especially in experimental teaching, has gained significant achievement. However, there are also some problems hindering further improvement of the teaching level and quality of this course. This thesis will discuss the methods of experimental teaching of econometrics by combining the author's teaching practice.

With the increased use of computer technology and software in econometrics instruction and learning, additional research and discussion is needed on the appropriate ways to apply computers and software in econometric classroom in order to get the students more interested in econometrics.

\section{From MATHEMATICAL METHOD TO ECONOMIC Model IN REALITY}

When mathematical methods and statistical techniques are applied to the analysis of economic problems and issues, the term usually applied to the process of applied economics is econometrics. The goal of econometrics is the development of valid, reliable, and value free predictive models of economic phenomena. Alan Greenspan stressed the importance of econometric models as a means of providing a clear understanding of economic events. He argued that the greatest advantage of a "ully articulated model is that it helps the forecaster keep track of the interrelationships among the primary variables of interest". Within the context of this argument, he referred to "simple accounting identity, such as the one that links government budget deficits, the current account balance, and the excess of domestic saving over investment," and "behavioral interdependencies," which "usually are subject to substantial uncertainty and, as a result, tend to be the focus of greater controversy. Taken together, 
identities and behavioral equations can aid the forecaster in tracing out a sequence of complicated interactions".

In some courses of econometrics at present, the content mostly focuses on mathematical method, with little emphasis on economic content and application of econometric model, and the economic methods are out of line with application of the model. The teachers also attach importance to strict mathematical derivation and ignore the issue of practice and application of econometric model. What's worse, the experimental teaching mode of econometrics cannot meet the requirement of subject development. So it is imperative to reform the experimental teaching mode. Econometrics is an instrumental course with practical nature, which requires eliminating the gap between the theory and the practice by means of experimental teaching.

The so-called experimental teaching refers to providing appropriate real background for the theories and methods to let students experience the necessity and effectiveness of each theory and method and understand corresponding theories and methods in this process through thorough analysis on the problems to be solved in reality. A common problem that an experimental teaching lacking cases causes are that the students misunderstand the nature of the course holding that econometrics is statistics or mathematics and thus appearing fear and lack of interest.

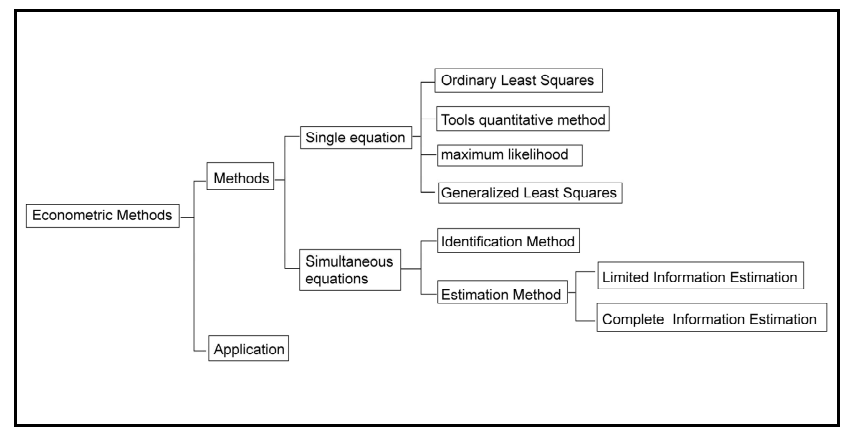

FIGURE I. ECONOMETRIC METHODS

\section{BUILDING EXPERIMENTAL TEACHING PLATFORM OF ECONOMETRICS}

Econometrics is a specific method within the general field of economics. The purpose of teaching economics in general is to provide an understanding of the workings of the economic system. But it is also important to acquaint the student with the problems and methods of economic policy. Hence it may be in the interest of the government to participate in and to encourage the teaching of economics in general and also of econometrics. At the same time, econometrics has important applications to problems in the private sector of the economy such as marketing, planning of production, etc. In general it appears that, apart from the United States, most institutions that teach econometrics are partly or wholly publicly supported. Only one institution outside the United States (namely in the United Kingdom) reported being entirely supported by private funds. One institution in France, one in India, and five of the sixteen reporting institutions in the United Kingdom indicated both private and public support.

With the rapid development of computer and network technologies, it becomes more and more convenient for people's living and learning. In order to save the limited and precious classroom teaching time and improve teaching effect, network learning platform should be established by taking full advantage of network resources. Each associated institution should build the network learning platform of econometrics with joint efforts. At the beginning, each associated institution can firstly establish their independent learning platform, which should cover such items as teaching courses, syllabus, database of cases, database of exercises, software support, updates and interaction between teachers and students.

As the resources construction of each associated institutions improves, all the platforms of econometric courses can be joined to form an integrated platform so that the students can share course resources from other schools and conduct network communication with students and teachers from other schools. By then, not only the students can have abundant learning resources, but also advanced students can provide further help and support. To build such network platform of courses will definitely need support and cooperation of each associated institutions and the supervisory departments.

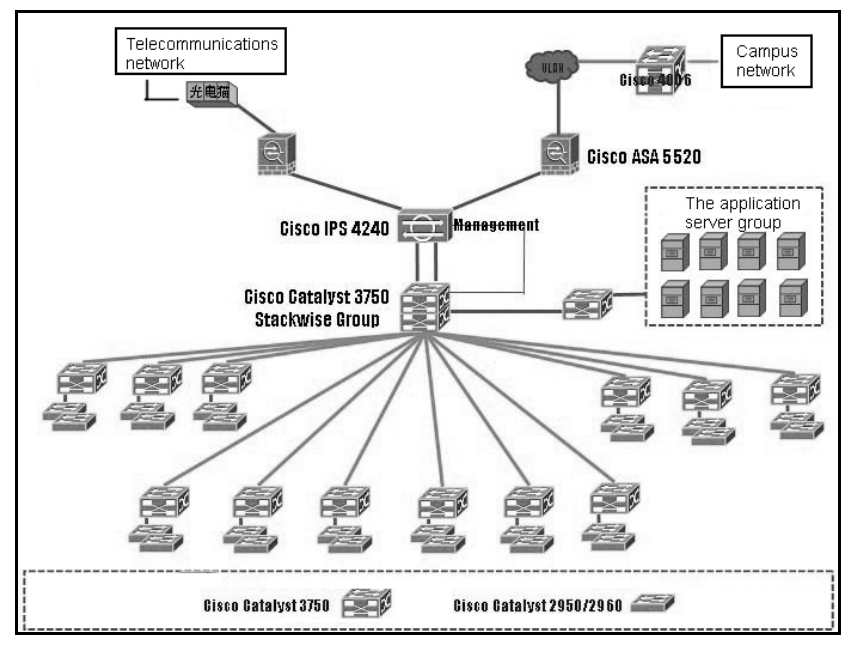

FIGURE II. THE STRUCTURE OF NETWORK RESOURSES

\section{Cultivating Student's CReative Ability in EXPERIMENTAL TEACHING}

The key to cultivate student's creative ability lies in renewing the thoughts on education and change the opinions of education. Firstly, in teaching, the opinion of teacherorientation should be changed into that of student-orientation guided by teacher to bring their enthusiasm, initiative and creativity into full play. Secondly, the view of knowledge education should be changed into that of ability and quality education, to build an appropriate and characteristic system of knowledge and ability structure. Meanwhile, teaching method should be reformed by reinforcing student's practical ability and creative awareness, which is the path and method for cultivating creative ability. 


\section{A. To Revitalize Teaching Methods and Improve Teaching Approaches}

Currently, the talents that we cultivate have a good understanding of theoretical knowledge, but insufficient creative spirit and ability. To seek the reason, one of the main points is that there is flaw in teaching method. Therefore, the teaching method must be reformed to strengthen cultivating creative spirit and ability. The major mission of reforming teaching method is to fully utilize the modern education technologies and approaches, conduct diversified teaching, change traditional teaching mode, firmly revitalize teaching method, advocate students to innovate and create, encourage their personality development, actively cultivate their spirit of taking initiative to learn, to explore and make progress, encourage and guide them to raise question and solve problems during teaching.

Following are an example, which shows the process of student uses Time Series Analysis Method to analysis model the Housing Prices of Four Cities in America in the classroom with independently:

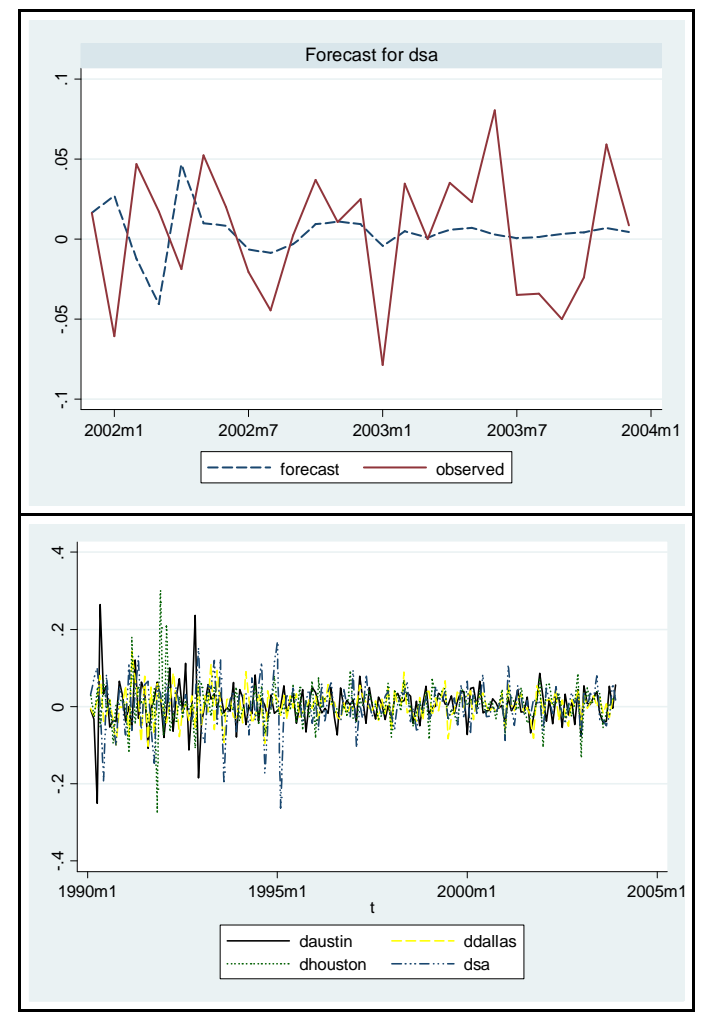

FIGURE III.
NEW TEACHING METHODS: COMPUTERASSISTED INSTRUCTION-1
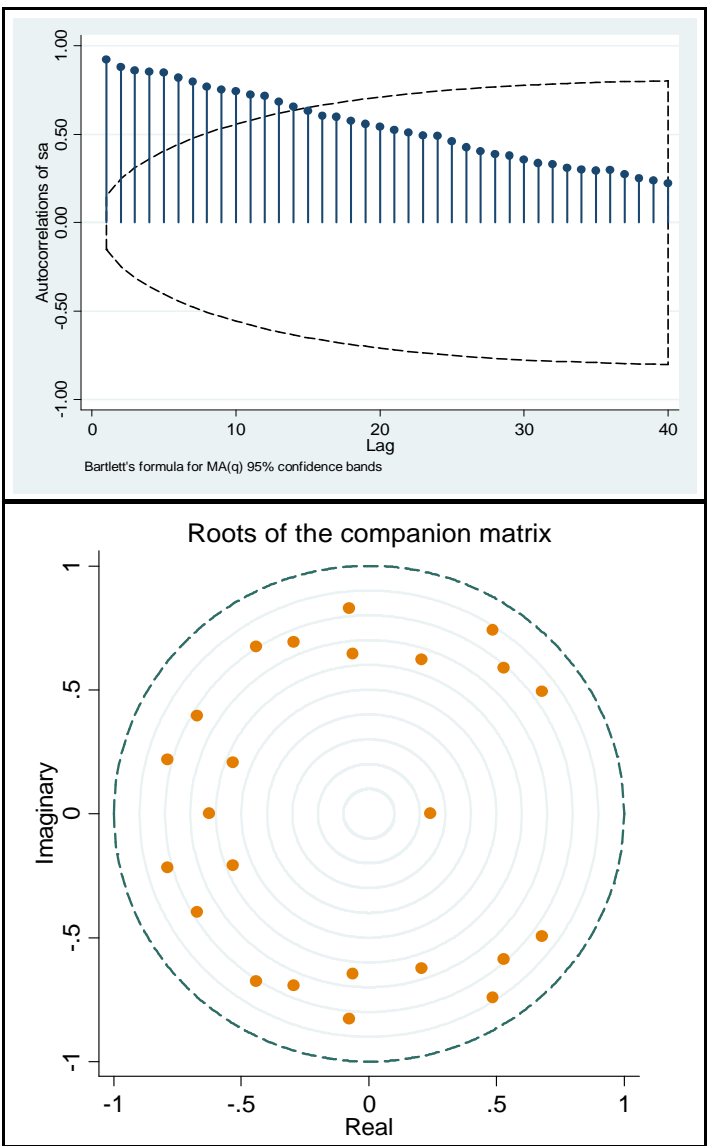

FIGURE IV. NEW TEACHING METHODS: COMPUTERASSISTED INSTRUCTION-2

In actual teaching, when lecturing contents of relatively strong operability, traditional blackboard teaching is of small volume and abstract; so computer experiment is utilized, which not only arouses student's interest, but also stirs their creative thoughts, able to achieve the ideal effect of increasing teaching quality and efficiency.

\section{B. To Alaborately Select Experiment Content and Scientifically Organize Experimental Teaching}

Against the features of strong practicability and plenty training contents of econometrics courses, only elaborately selected content, scientific organization and reasonable arrange in limited sessions can help achieve the purpose of cultivating student's creative ability. Selection of experimental subject should adhere to such basic principles as reinforcing foundation, highlighting comprehensiveness and focusing on ability. To reinforce learning and training of fundamental contents is helpful to understanding and grasping experimental essence and laying foundation for cultivating the student's resilience of accepting new things and creative awareness. In the experimental teaching of econometrics, the monotonous and verification-type teaching mode should be changed into leveldividing and question-type teaching, to be dedicated to developing student's intelligence. The effect of such teaching mode is relatively good because it not only meets the requirement of common theory and experimental teaching, but 
also cultivates student's applying ability and independent creative spirit through subject study. Adopting such initiative experimental teaching mode is the specific manifestation of creative education thought in the experimental teaching in higher education institutions. It is an experimental teaching mode that can cultivate student's creative spirit, research ability and scientific literacy. Through initiative experimental teaching, enabling students to find and learn new knowledge and new things, and grasp new methods, which lay a foundation for them to become creative talents with high quality.

In order to guide the students of different grades and intelligence to have the feeling of "climbing", difference should be made in such aspects as difficulty of selected subject and experimental requirement. Experience has proved that such teaching system can not only guarantee student's basic training, but also cultivate their ability in independent thinking and making breakthrough. It can strengthen their confidence and bring their brilliant intelligence into full play by teaching the students according to their aptitude. Besides, it has created good conditions for excellent students to stand out and develop personalities.

\section{CONCLUSION}

To sum up, experimental teaching of econometrics is a very comprehensive subject, which has relatively high requirement on both students and the teacher. What both our extensive teachers and workers of experimental teaching should think over is how to cultivate student's creative ability in analyzing and solving actual problems by flexibly using these tools while being able to teach basic theoretical knowledge and make them grasp basic software operation.

With the development of econometric on the world, it has been an indispensable tool in solving of economic problems. Teacher who devote their efforts to econometrics should explore the study resource and teaching methods on econometric.

We should change force-feeding teaching to heuristic teaching, using case analysis and scene teaching to help open students' thinking gate. We should construct a ClassroomLaboratory-Social practice education system of threedimensional diversification and cultivate students' independent thinking and analysis ability. It well help students to solve practical problems by checking related materials and learn what they need, to control such subjects as economics, finance, calculus, linear algebra, probability theory and mathematical statistics, computer software applications and knowledge of other disciplines better, and to form a multi-disciplinary knowledge, skills and innovation, the high level of cross.

\section{REFERENCES}

[1] Gerhard Tintner "The teaching of econometrics," Econometrica. , Vol. 22, No. 1

[2] T. M. F. Smith, L. Staetsky, "The teaching of statistics in UK Universities", Journal of the Royal Statistical Society. Series A (Statistics in Society), Vol. 170, No. 3 (2007)

[3] James A. Davis, "Teaching social facts with computers teaching social facts with computers," Teaching Sociology, Vol. 5, No. 3 (Apr., 1978).
[4] Daniel L. Rubinfeld, "Econometrics in the courtroom econometrics in the courtroom," Columbia Law Review, Vol. 85, No. 5 (Jun., 1985),

[5] Rolf Nevanlinna "Reform in teaching mathematics reform in teaching mathematics," The American Mathematical Monthly, Vol. 73, No. 5 (May, 1966).

[6] John C. Soper, "Computer-assisted instruction in economics: a survey computer-assisted instruction in economics," The Journal of Economic Education, Vol. 6, No. 1 (Autumn, 1974).

[7] Anand Desai, "Quantitative methods, economics, and or models quantitative methods, economics, and or models," Journal of Policy Analysis and Management, Vol. 27, No. 3 (Summer, 2008). 